the establishment of infrastructure, Yelda Bilginer Grant/research support from: Novartis and SOBI financially supported the HELIOS registry during the establishment of infrastructure, Seza Özen Consultant of: Novartis, Pfizer, Speakers bureau: SOBI, Novartis

DOI: 10.1136/annrheumdis-2020-eular.1313

\begin{tabular}{|l|l}
\hline OP0290 & EMAPALUMAB (ANTI-INTERFERON-GAMMA \\
MONOCLONAL ANTIBODY) IN PATIENTS WITH \\
MACROPHAGE ACTIVATION SYNDROME (MAS) \\
COMPLICATING SYSTEMIC JUVENILE IDIOPATHIC \\
ARTHRITIS (SJIA)
\end{tabular}

F. De Benedetti ${ }^{1}$, P. Brogan ${ }^{2}$, C. Bracaglia ${ }^{1}$, M. Pardeo ${ }^{1}$, G. Marucci ${ }^{1}$, E. Sacco ${ }^{1}$, D. Eleftheriou, ${ }^{2}$ C. Papadopoulou' ${ }^{2}$, A. Grom ${ }^{3}$, P. Quartier ${ }^{4}$, R. Schneider ${ }^{5}$, P. Jacqmin ${ }^{6}$, R. Frederiksen ${ }^{7}$, M. Ballabio ${ }^{7}$, C. De Min ${ }^{7} .{ }^{1}$ IRCCS Ospedale Pediatrico Bambino Gesù, Rheumatology, Rome, Italy; ${ }^{2}$ UCL Institute of Child Health, and Great Ormond Street Hospital NHS Foundation Trust, Section Head Infection, Immunology, and Rheumatology, London, United Kingdom; ${ }^{3}$ Cincinnati Children's Hospital, Division of Rheumatology, Cincinnati, United States of America; ${ }^{4}$ Paris-Descartes University, IMAGINE Institute, RAISE Reference Centre, Pediatric Immuno-Hematology and Rheumatology Unit, Necker Hospital, Assistance Publique-Hôpitaux de Paris, Paris, France; ${ }^{5}$ The Hospital for Sick Children, Department of Pediatrics, Division of Rheumatology, Toronto, Canada; ${ }^{6}$ MnS Modelling and Simulation, Dinant, Belgium; ${ }^{7}$ Swedish Orphan Biovitrum AG (Sobi), Basel, Switzerland

Background: MAS is a severe complication of rheumatic diseases and occurs most frequently in patients with sJIA. Data from animal models and from observational studies in patients suggest that interferon gamma (IFNy) is a driver of the hyperinflammation and hypercytokinemia observed in MAS.

Objectives: To assess the pharmacokinetics, efficacy, and safety of intravenous (IV) infusions of emapalumab, a fully human anti-IFNY monoclonal antibody, in patients with MAS in the context of sJIA.

Methods: This ongoing, pilot, open-label, single-arm study (NCT03311854) includes patients with MAS (2016 ACR/EULAR criteria) on a background of confirmed, or high presumption of, SJIA, and with inadequate response to high-dose IV glucocorticoids. Emapalumab is initiated at $6 \mathrm{mg} / \mathrm{kg}$ (1 dose) and continued at $3 \mathrm{mg} / \mathrm{kg}$ twice weekly for a total of 4 weeks, or less upon achievement of complete response (CR). CR is defined as an absence of MAS clinical signs plus white blood cell and platelet counts above the lower limit of normal, LDH, AST and ALT $<1.5 \times$ upper limit of normal, fibrinogen $>100 \mathrm{mg} / \mathrm{dL}$, and ferritin decreased by $\geq 80 \%$ or to $<2,000 \mathrm{ng} / \mathrm{mL}$.

Results: We report preliminary data from the first 9 patients (median age [range] 11.6 [2.1-25.3] years) enrolled ( 7 in Europe and 2 in the USA). All patients had failed high-dose methylprednisolone, of which there were prior treatment failures from cyclosporin $A(n=4)$ and from anakinra $(n=4)$. Treatment with emapalumab resulted in rapid IFNY neutralization, as demonstrated by the decrease in CXCL9 levels (Figure 1), and subsequent deactivation of $T$ cells, as indicated by the decrease in sIL-2R levels. CR was achieved in all patients after a median of 23 (12-56) days. A progressive improvement in all clinical and laboratory parameters of MAS was observed (Table 1 and Figure 2). Glucocorticoids were tapered in all patients (median \% tapering $-92 \%$; range $-45 \%$ to $-98 \%$ at Week 8 ). Emapalumab infusions were well tolerated by all patients, with no discontinuation. CMV reactivation was reported in 1 patient as a serious event possibly related to emapalumab and resolved with antiviral treatment.

Table 1. Time to response for key clinical and laboratory parameters.

\begin{tabular}{lcc}
\hline Parameters & $\begin{array}{c}\text { Median baseline value } \\
\text { (range) }\end{array}$ & $\begin{array}{c}\text { Median days of } \\
\text { treatment (range) }\end{array}$ \\
\hline D-dimers to $<1000 \mathrm{mg} / \mathrm{L}$ & $12,480(550-89,552)$ & $15(1-49)$ \\
sIL-2R to $<2000 \mathrm{ng} / \mathrm{L}$ & $4596(1664-20,954)$ & $21(6-37)$ \\
Ferritin $<500 \mathrm{mg} / \mathrm{L}$ & $29,240(716-192,584)$ & $21(9-42)$ \\
Physician visual analog scale of MAS activity $\leq 1$ & $9.0(2-10)$ & $19(9-56)$ \\
$\begin{array}{l}\text { All MAS laboratory parameters within range } \\
\text { of CR }\end{array}$ & NA & $21(15-55)$ \\
All MAS parameters within range of CR & NA & $23(12-56)$ \\
Glucocorticoid tapering at $\leq 1$ mg/kg predniso- & NA & $42(16-50)$ \\
$\quad$ lone equivalent* & & \\
\hline
\end{tabular}

${ }^{\star}$ Data incomplete for 1 patient

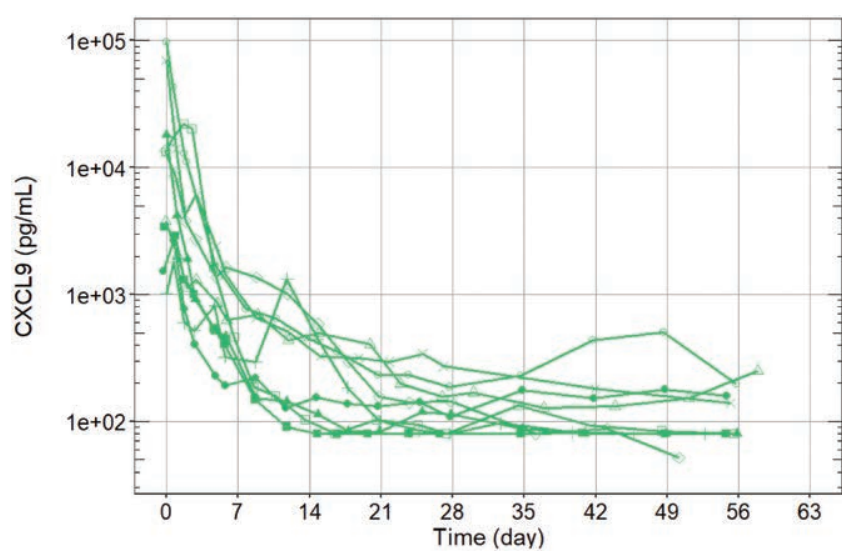

Figure 1. Rapid neutralization of IFNy. Each line represents an individual patient $(n=9)$.

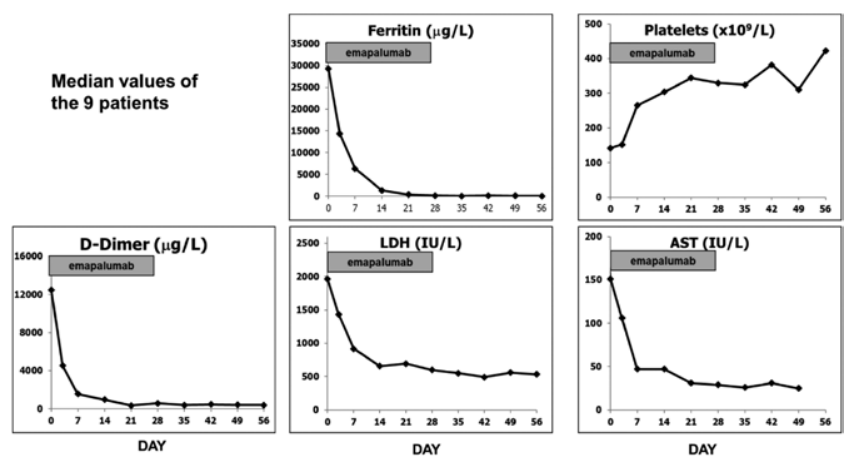

Figure 2. Ferritin levels and platelet counts over time.

Conclusion: Emapalumab administration led to rapid neutralization of IFNy and was efficacious in controlling MAS with a favorable safety profile. These results support the pathogenic role of IFNY in MAS/sJIA and the therapeutic value of IFNy neutralization in MAS patients who have failed standard of care.

Disclosure of Interests: Fabrizio De Benedetti Grant/research support from: AbbVie, Pfizer, Novartis, Novimmune, Sobi, Sanofi, Roche, Speakers bureau: AbbVie, Novartis, Roche, Sobi, Paul Brogan Grant/research suppor from: Sobi, Novartis, Roche, Chemocentryx, Consultant of: Roche, Sobi, Speakers bureau: Sobi, Roche, Novartis, UCB, Claudia Bracaglia: None declared, Manuela Pardeo: None declared, Giulia Marucci: None declared, Emanuela Sacco: None declared, Despina Eleftheriou Speakers bureau: Sobi, Charalampia Papadopoulou: None declared, Alexei Grom Grant/ research support from: Novartis, AB2Bio, Consultant of: Novartis, Pierre Quartier Consultant of: AbbVie, Chugai-Roche, Lilly, Novartis, Sanofi, Sobi, Speakers bureau: AbbVie, BMS, Chugai-Roche, Novartis, Pfizer, Sobi, Rayfel Schneider Grant/research support from: Roche, Novartis, Sobi, Pfizer Consultant of: Sobi, Novartis, Novimmune, Philippe Jacqmin Consultant of: Sobi, Rikke Frederiksen Employee of: Sobi, Maria Ballabio Employee of: Sobi, Cristina De Min Employee of: Sobi

DOI: 10.1136/annrheumdis-2020-eular.3169

\section{OP0291 TOFACITINIB FOR THE TREATMENT OF POLYARTICULAR COURSE JUVENILE IDIOPATHIC ARTHRITIS: RESULTS OF A PHASE 3, RANDOMISED, DOUBLE-BLIND, PLACEBO-CONTROLLED WITHDRAWAL STUDY}

N. Ruperto ${ }^{1}$, O. Synoverska ${ }^{1}$, T. Ting ${ }^{2}$, C. Abud-Mendoza ${ }^{1}$, A. Spindler ${ }^{1}$, Y. Vyzhga' ${ }^{1}$, K. Marzan ${ }^{2}$, V. Keltsev ${ }^{1}$, I. Tirosh ${ }^{1}$, L. Imundo ${ }^{2}$, R. Jerath ${ }^{2}$, D. Kingsbury ${ }^{2}$, B. Sözeri ${ }^{1}$, S. Vora ${ }^{2}$, S. Prahalad ${ }^{2}$, E. Zholobova ${ }^{1}$, Y. Butbul Aviel $^{1}$, V. Chasnyk ${ }^{1}$, M. Lerman ${ }^{2}$, K. Nanda ${ }^{2}$, H. Schmeling ${ }^{2}$, H. Tory ${ }^{2}$, Y. Uziel' ${ }^{1}$,

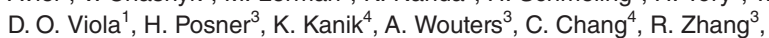
I. Lazariciu ${ }^{5}$, M. A. $\mathrm{Hsu}^{4}$, R. Suehiro ${ }^{6}$, A. Martini ${ }^{1}$, D. J. Lovell ${ }^{2}$, H. Brunner ${ }^{2}$ on behalf of PRINTO/PRCSG. ${ }^{1}$ PRINTO, Istituto Giannina Gaslini, Genova, Italy; ${ }^{2}$ PRCSG, Cincinnati Children's Hospital Medical Center, Cincinnati, OH, United States of America; ${ }^{3}$ Pfizer Inc, New York, NY, United States of America; ${ }^{4}$ Pfizer Inc, Groton, CT, United States of America; ${ }^{5}$ IQVIA, Montreal, QC, Canada; ${ }^{6}$ Pfizer Inc, Collegeville, PA, United States of America 